\title{
Pneumatosis intestinalis: Diagnosis by endoscopic ultrasound-guided puncture
}

\author{
Rafie A. Yakoob, Manik Sharma, Hamid U. Wani \\ Department of Medicine, Division of Gastroenterology, Hamad Medical Corporation, Doha, Qatar
}

\begin{abstract}
\end{abstract}
\section{Introduction}

Pneumatosis intestinalis (PI) is a benign idiopathic condition in which multiple thin-walled cysts of varying size develop in the submucosa or subserosa of the bowel wall. The subserosal cysts are most frequently found in the small bowel while the submucosal cysts are predominantly seen in the colonic wall. When the cysts protrude into the lumen, they may mimic polyps or submucosal masses. We report this case in association with severe constipation and diagnosis was confirmed on endoscopic ultrasound (EUS).

\section{Case Report}

A 53-year-old male patient not known to have any chronic medical disease presented with history of constipation and painful defecation. The patient denied any history of abdominal pain or bleeding per rectum. The patient had hemorrhoidectomy for bleeding hemorrhoids 15 months

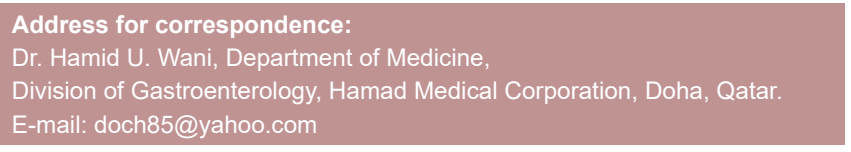

\begin{tabular}{|l|c|}
\hline \multicolumn{2}{|c|}{ Video available on: www.jdeonline.in } \\
\hline \multicolumn{2}{|c|}{ Access this article online } \\
\hline \multirow{2}{*}{$\begin{array}{l}\text { Website: } \\
\text { www.jdeonline.in }\end{array}$} & Quick Response Code \\
\hline DOI: & \\
10.4103/0976-5042.193739 & \\
&
\end{tabular}

back. Colonoscopy was done using Pentax Colonoscope, Model 38-i10L, Channel 3.8, which revealed cluster of cystic submucosal lesions of varying sizes with normal overlying mucosa in the rectosigmoid [Figure 1a and b]. On computed tomography (CT) scan, there was thickening of the rectosigmoid with foci of air within the bowel wall [Figure 2]. EUS by radial Pentax EUS scope, EG-3670 URK, showed anechoic submucosal lesions [Figure 3] which collapsed on needle puncture. Puncturing was done using radial EUS scope, EG-3670 URK by 2.3 injection needle [Video 1]. The patient was started on laxatives and his symptoms improved without any intervention.

\section{Discussion}

The exact etiology of PI is not known but association with multiple benign and life-threatening conditions has been reported. ${ }^{[1]}$ PI has been classified into primary and secondary forms. Primary PI is a benign idiopathic condition in which multiple thin-walled cysts develop in the colon. Most often, this form has no symptoms and the cysts may be found incidentally through radiography or endoscopy. When the cysts protrude into the lumen, they may mimic polyps or carcinoma. The secondary form of PI is a secondary finding

This is an open access article distributed under the terms of the Creative Commons Attribution-NonCommercial-ShareAlike 3.0 License, which allows others to remix, tweak, and build upon the work non-commercially, as long as the author is credited and the new creations are licensed under the identical terms.

For reprints contact: reprints@medknow.com

How to cite this article: Yakoob RA, Sharma M, Wani HU. Pneumatosis intestinalis: Diagnosis by endoscopic ultrasound-guided puncture. J Dig Endosc 2016;7:110-1. 


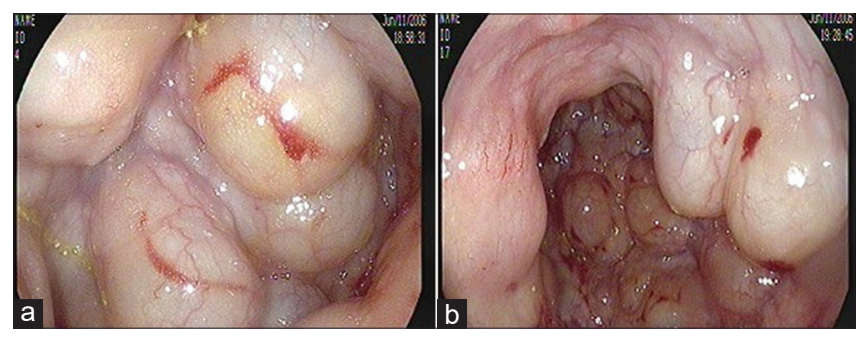

Figure 1: ( $a$ and b) Cystic submucosal lesions consistent with pneumatosis intestinalis

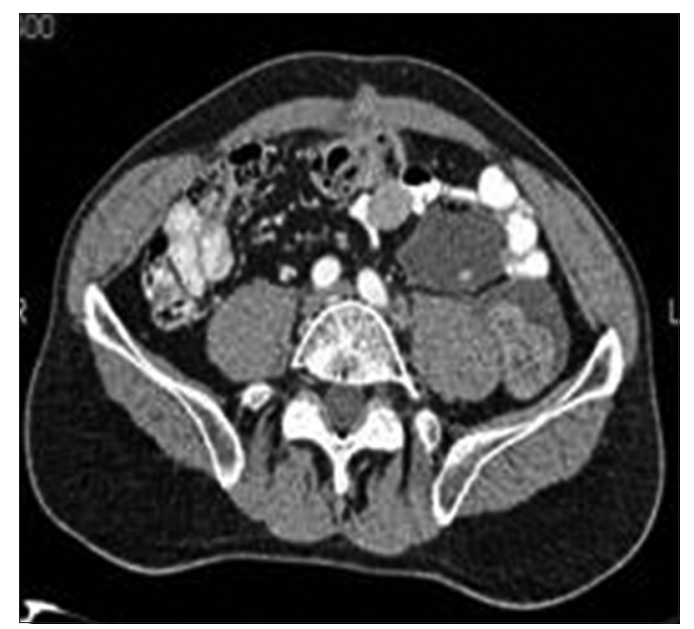

Figure 2: Computed tomography axial film showing foci of air within the bowel wall

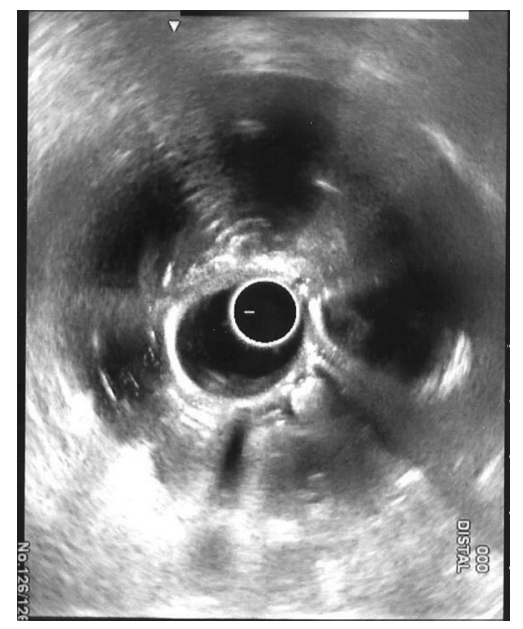

Figure 3: Radial endoscopic ultrasound image showing submucosal anechoic lesions

caused by underlying diseases. It is found in association with chronic obstructive pulmonary disease, connective tissue disorders, infectious enteritis, amyloidosis, acquired immune deficiency syndrome with organ transplantation, steroid use, and chemotherapy. ${ }^{[2]}$ Defective mucosal integrity, increased intraluminal pressure, and excessive intraluminal gas by abnormal bacterial flora have been implicated in the formation of the pneumocystis. ${ }^{[3,4]} \mathrm{PI}$ presents with mild gastrointestinal symptoms. Symptoms include diarrhea, mucus discharge, rectal bleeding, and constipation. ${ }^{[5,6]} \mathrm{PI}$ is usually identified on plain radiographs of the abdomen. The diagnosis suspected by radiography or endoscopy is confirmed by $\mathrm{CT},{ }^{[7]} \mathrm{PI}$ is an ominous finding in ischemia. The association of gas in the mesenteric and portal circulation is an ominous radiographic finding in bowel ischemia. On colonoscopy, there may be difficulty to differentiate PI from more common diseases of the colon ${ }^{[8]}$ In the colon, PI is often misdiagnosed as polyps, carcinoma, and lymphoma. EUS can help differentiate anechoic submucosal lesions from hyperechoic solid lesions of the colon.

EUS is a safe and accurate diagnostic tool to differentiate PI from polyps or submucosal masses in difficult to diagnose cases. Surgery should be performed in patients who are not responding to nonoperative treatment, especially those with signs of perforation, peritonitis, or abdominal sepsis.

\section{Financial support and sponsorship Nil.}

\section{Conflicts of interest}

There are no conflicts of interest.

\section{References}

1. Wu LL, Yang YS, Dou Y, Liu QS. A systematic analysis of pneumatosis cystoids intestinalis. World J Gastroenterol 2013;19:4973-8.

2. Greenstein AJ, Nguyen SQ, Berlin A, Corona J, Lee J, Wong E, et al. Pneumatosis intestinalis in adults: Management, surgical indications, and risk factors for mortality. J Gastrointest Surg 2007;11:1268-74.

3. Ho LM, Paulson EK, Thompson WM. Pneumatosis intestinalis in the adult: Benign to life-threatening causes. AJR Am J Roentgenol 2007;188:1604-13.

4. St Peter SD, Abbas MA, Kelly KA. The spectrum of pneumatosis intestinalis. Arch Surg 2003;138:68-75.

5. Heng Y, Schuffler MD, Haggitt RC, Rohrmann CA. Pneumatosis intestinalis: A review. Am J Gastroenterol 1995;90:1747-58.

6. Chaput U, Ducrotté P, Denis P, Nouveau J. Pneumatosis cystoides intestinalis: An unusual cause of distal constipation. Gastroenterol Clin Biol 2010;34:502-4.

7. Mavrogenis G, Chapeaux X, Benali V, Warzée P. Pneumatosis cystoides intestinalis: Modern diagnostic modalities. Dig Liver Dis 2013;45:617.

8. Höer J, Truong S, Virnich N, Füzesi L, Schumpelick V. Pneumatosis cystoides intestinalis: Confirmation of diagnosis by endoscopic puncture a review of pathogenesis, associated disease and therapy and a new theory of cyst formation. Endoscopy 1998;30:793-9. 